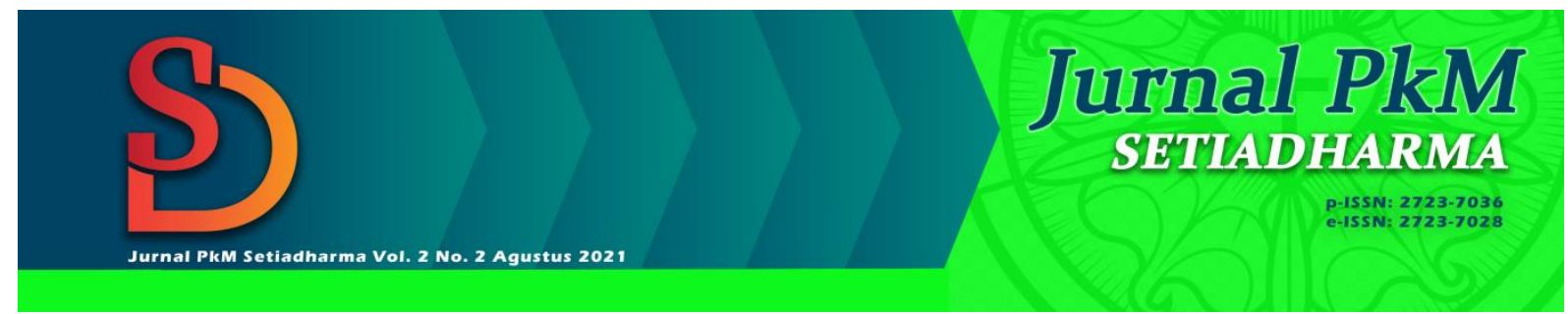

\title{
PENERAPAN METODE PEMBELAJARAN PAAIKES UNTUK MENINGKATKAN ANTUSIASME ANAK SEKOLAH MINGGU DALAM BERIBADAH ONLINE DI GBI PAPUA RESTORATION FOR CHRIST
}

\author{
Yohanes Charly Panjaitan, Ferdinand Edu, Ivonne Sandra Sumual \\ 123 Sekolah Tinggi Teologi Bethel Indonesia \\ yohanescharly47@gmail.com,Ferdinanedu@sttbi.ac.id,Ivonnesandra@sttbi.ac.id
}

\section{Diterima: \\ 16-07-2021}

Direview:

22-07-2021

18-08-2021

Direvisi:

11-08-2021

24-08-2021

Diterbitkan:

30-08-2021

Keywords:

children, church; teacher, enthusiasm, sunday school

Kata Kunci: anak ; gereja; guru; antusiasme; Sekolah Minggu

\section{Abstract}

During the Covid-19 pandemic, Sunday School Teachers are required to be able to carry out Sunday school worship properly with the essence and the right way. This is so that children do not experience boredom and can understand the material presented correctly and experience growth in faith according to their age. Therefore, the team carried out Community Service at GBI Papua Restoration For Christ by applying the PAAIKES teaching method to Sunday school children. The implementation method is carried out by teaching and mentoring. The results of PkM stated that the response was enthusiastic and enthusiastic from Sunday School children when worshiping and listening to God's word. Enthusiastic Sunday School children can be owned by the church if they apply the right teaching methods and give full attention such as providing the right mentoring and direction

\section{Abstrak}

Pada masa pandemi Covid-19, Guru Sekolah Minggu dituntut untuk mampu menjalankan ibadah sekolah minggu sebagaimana mestinya dengan esensi dan cara yang tepat. Hal ini supaya anak-anak tidak mengalami kebosanan dan dapat memahami materi yang disampaikan dengan benar dan mengalami pertumbuhan iman sesuai dengan usianya. Karena itu, tim melakukan Pengabdian kepada Masyarakat di GBI Papua Restoration For Christ dengan menerapkan metode mngajar PAAIKES kepada anak-anak sekolah minggu. Metode pelaksanaan dilakukan dengan pengajaran dan pendampingan. Hasil PkM menyatakan bahwa respons antusias dan semangat dari anak Sekolah Minggu ketika ibadah dan mendengarkan firman Tuhan. Anak Sekolah Minggu yang antusias dapat dimiliki oleh gereja jika menerapkan metode mengajar yang tepat dan memberikan perhatian penuh seperti melakukan pendampingan serta arahan yang tepat. 


\section{PENDAHULUAN}

Usia anak memiliki kecenderungan untuk bermain dengan melibatkan aktivitas fisik. Berlari, melompat, dan kegiatan fisik lainnya dilakukan dengan ceria. Masa anakanak juga adalah masa pengisian pengetahuan akan dunia secara luas yang pada masa depan akan dipegang sebagai informasi yang benar. ${ }^{1}$ Rangkaian kegiatan anak yang bernilai ini dapat dilakukan oleh sekolah formal anak, dan informal. Sekolah informal bagi orang Kristen adalah sekolah minggu anak. Namun, bagaimana dengan masa pandemi saat ini? Tentunya kegiatan itu terhambat dan menjadi kesulitan tersendiri bagi orang tua dan guru sekolah minggu.

Peranan guru sekolah minggu menjadi penting dalam tumbuh kembang anak dikarenakan faktor kepatuhan yang tinggi dari anak-anak. Guru sekolah minggu dianggap sebagai pribadi yang dapat memberikan informasi yang bersifat rohani kepada anak-anak. Tetapi, kendala akibat pademi covid-19 ini. ${ }^{2}$ Dalam melaksanakan tugas untuk mendidik anak Sekolah Minggu, dibutuhkan seorang pengajar yang kompeten dan profesional. ${ }^{3}$ Untuk menjadi guru yang memiliki kreativitas dibutuhkan proses yang menuntut pengajar lebih cakap, terampil, dan memiliki motivasi yang kuat. ${ }^{4}$ Kreativitas diartikan sebagai kemampuan seseorang untuk menciptakan ide atau wawasan berupa konsep sesuatu yang belum pernah ada, maupun yang sudah pernah ada namun dikembangkan dengan mengelaborasikan apa yang ada dalam diri dan daerah sekitar. ${ }^{5}$ Munandar memberikan komentarnya terhadap makna kreativitas sebagai keahlian dari seseorang dalam create hal baru, memberi gagasan baru yang dapat dilakukan dalam memecahkan masalah, dan untuk melihat hubungan baru dengan unsur yang sudah ada sebelumnya. ${ }^{6}$ Slameto menegaskan bahwa hal yang penting dalam Kreativitas bukan penemuan sesuatu yang belum pernah ada, melainkan Kreativitas yang merupakan hal baru bagi diri sendiri dan tidak harus merupakan sesuatu yang baru bagi orang lain secara umum ${ }^{7}$

Kreativitas itu amat dibutuhkan dalam mengajar anak-anak Sekolah Minggu. Kepentingannya bukan hanya supaya anak senang mengikuti ibadah yang ada, melainkan peranannya dalam membangun kehidupan rohani anak (iman) yang akan menentukan cara pandang mereka kelak setelah dewasa. Tujuan ini dapat tersampaikan jika kegiatan, firman, dan pujian dan penyembahan yang ada di sekolah minggu berjalan dengan kreativitas. Menjadi masalah tersendiri akan hal itu, sebab daya tahan dan konsentrasi anak yang masih amat rendah. Melalui penelitian, didapati bahwa kelas Batita hanya sekitar 5 menit, kelas Kecil ada di range 7-10 menit, kelas Tengah antara 10-15 menit, kelas Besar antara 20-25 menit. ${ }^{8}$ Dengan keadaan anak seperti ini, maka kreativitas dari guru sekolah minggu adalah kunci utama dalam keberhasilan mengajarkan kebenaran firman Tuhan kepada anak .

${ }^{1}$ Jodi Hoch, Janet Lee, and Susan, Berbagai Aktivitas Asyik Untuk Anak Di Sekolah Minggu Kelompok Bermain Dan Rumah (Jakarta: BPK Gunung Mulia, 2004). 118.

2 Meike Kurniawati and Ninawati, "Seminar Mengajar Kreatif," Prosiding Seminar Hasil Pengabdian Kepada Masyarakat (2018): 468-472.

3 Tanto Kristiono and Deo Putra Perdana, "Hambatan Dan Pelayanan Guru Sekolah Minggu Di Gereja Kristen Jawa Jebres Surakarta” 1, no. 2 (2019): 91.

${ }^{4}$ Utami Munandar, Pengembangan Kreativitas Anak Berbakat (Jakarta: Rineka Cipta, 2009), 18.

${ }^{5}$ Kurniawati and Ninawati, "Seminar Mengajar Kreatif."

6 Utami Munandar, Mengembangkan Bakat Dan Kreativitas Anak Sekolah (Jakarta: Gramedia Widiasarana Indonesia, 2012).

7 Slameto, Belajar Dan Faktor-Faktor Yang Mempengaruhi (Jakarta: Rineka Cipta, 2010), 146.

${ }^{8}$ Kurniawati and Ninawati, "Seminar Mengajar Kreatif." 
PENERAPAN METODE PEMBELAJARAN PAAIKES ... (Yohanes Charly Panjaitan, Ferdinand Edu, Ivonne Sandra Sumual)

Tantangan yang telah dipaparkan di atas terlihat jelas di GBI Papua Restoration For Christ. Sebelum masa pandemi covid-19 masalah itu telah ada, dan diperparah lagi dengan adanya pandemi covid-19 katika ibadah dilaksanakan di rumah masing-masing. Penurunan jumlah pun tidak terelakkan. Dari jumlah anak-anak yang hadir setiap minggu 10 orang, dengan ibadah online maka tidak ada yang hadir. Karenanya, gereja menghentikan kegiatan sekolah minggu sampai waktu yang tidak ditentukan. Ketika gereja melakukan kegiatan ibadah sekolah minggu hybrit pun orang tua dari anak tidak memberikan izin anaknya beribadah. Masalah lain adalah usia yang beragam dari anak sekolah minggu, dan jika dilakukan pengelompokan kepada anak-anak sesuai usianya, maka masalah lain muncul yaitu guru sekolah minggu yang hanya berjumlah 2 orang saja. Guru sekolah minggu ini pun kurang kreativitas dan interaksi dalam mengajar anak , dan lebih cenderung menjadi penjaga anak saja karena orang tuanya berada di ibadah umum. 2 orang guru sekolah minggu itu pun berusia 28 dan 50 tahun, yang berarti tidak relevan dengan anak-anak yang usianya antara 8-12 tahun.

\section{METODE PELAKSANAAN}

Metode penulisan artikel ini dilakukan dengan kualitatif desktriptif. Lokasi pelaksanaan kegiatan berada di GBI Papua Restoration For Christ. Kegiatan dilaksanakan selama 4 bulan penuh, yakni dari bulan Maret hingga Juni 2021, secara online dan onside. Pelaksanaan online dilaksanakan melaui aplikasi zoom meeting, rekaman, dan memberikan arahan melalui video di youtube. Sedangkan pelaksanaan onside dilakukan oleh salah satu anggota kelompok yang melayani di GBI Papua Restoration For Christ.

Tahapan kegiatan pada pelaksanaan Pengabdian Masyarakat Gereja terkait pelatihan pengembangan kreativitas dilakukan dengan metode pendekatan dan pendampingan. Pendekatan pelatihan yaitu melalui rekaman video pada zoom meeting, video diupload ke youtube sebagai bentuk interaksi dan kreativitas kepada anak Sekolah Minggu, selanjutnya metode pendampingan dalam berkomunikasi dengan para guru Sekolah Minggu.

Rangkaian kegiatan dalam Pengabdian Masyarakat Gereja dilakukan sebagai berikut:

1. Konfirmasi kepada gembala GBI Papua Restoration For Christ untuk meminta izin dan kesepakatan pelayanan bersama.

2. Mengkonfirmasi tempat Pengabdian Masyarakat Gereja kepada dosen pengampu.

3. Membuat rancangan pelaksanaan kegiatan dengan kelompok.

4. Melakukan pelayanan dengan metode pendekatan melalui rekaman video pada zoom meeting dan menyerahkan hasil rekaman video untuk ditayangkan oleh anggota kelompok di GBI Papua Restoration For Christ saat Sekolah Minggu berlangsung.

5. Melakukan pelayanan dengan metode pendampingan melalui diskusi dengan guru Sekolah Minggu menggunakan aplikasi zoom meeting.

6. Melakukan pemantauan dan evaluasi. Pada saat kegiatan berlangsung, setiap tahapan proses akan dilakukan pemantauan sesuai dengan rencana dan tujuan yang telah ditetapkan.

Metode penelitian yang digunakan adalah kualitatif deskriptif untuk memotret fenomena di lapangan, seperti perilaku, persepsi, motivasi, dan tindakan. Langkahlangkah yang dilakukan untuk mendapatkan tujuan itu sebagai berikut: (i) dilakukanlibrary research guna mendapatkan bahan ajar, kurikulum, dan kajian lainnya 
mengenai pelayanan sekolah minggu; (ii) melakukan observasi lapangan melalui kuisioner dengan memberikan kepada anak-anak untuk mengisinya, tentunya dibantu oleh orang tua anak, yang bertujuan mendapatkan data real peran guru sekolah minggu selama ini; (iii) melakukan wawancara tidak struktur dengan objek penelitian (pengawas guru sekolah minggu). Wawancara dilakukan dengan tujuan memperkuat dan validasi data angket sehingga data yang diperoleh jenuh.

\section{HASIL DAN PEMBAHASAN}

Metode mengajar yang digunakan guru Sekolah Minggu menjadi hal penting untuk diperhatikan. Hal ini dapat dilihat dari masalah yang terjadi di GBI Papua Restoration For Christ yang mengalami penurunan anak Sekolah Minggu secara kuantitas, khususnya di masa pandemi. Metode baru yang dapat menjawab kebutuhan dan memberi solusi dari masalah yang terjadi di GBI Papua Restoration For Christ dapat dijadikan sebagai acuan untuk mempertimbangkan, menilai, memeriksa dan menguji kemungkinan baru untuk memecahkan masalah dan memberi solusi menarik bagi anak Sekolah Minggu. ${ }^{9}$

Relasi yang baik, berlandaskan kasih, dan berusaha menolong antara guru Sekolah Minggu dengan anak Sekolah Minggu memberi pengaruh yang besar dalam meningkatkan antusias anak Sekolah Minggu dalam beribadah. ${ }^{10}$ Seorang Guru Sekolah Minggu diharuskan menyemangati peserta didiknya supaya ingin dan senang belajar kebenaran Firman Tuhan. Variasi saat memberitakan Firman Tuhan juga dapat digunakan untuk menarik minat anak-anak Sekolah Minggu datang beribadah dan mendengarkan firman Tuhan. Tetapi kenyataannya masih banyak gereja dengan guru Sekolah Minggu yang tidak demikian. Guru Sekolah Minggu sering terjebak pada ibadah dan penyampaian firman Tuhan dengan cara dan metode yang sama setiap minggu sehingga anak-anak Sekolah Minggu kurang termotivasi untuk belajar Alkitab. Salah satu faktor yang memberi pengaruh minat anak dalam beribadah adalah acara dan hal menarik lainnya dalam suasana kelas yang menyenangkan. ${ }^{11}$ Hal ini menunjukkan bahwa kualitas metode pembelajaran yang diterapkan oleh guru Sekolah Minggu memegang peranan yang sangat penting. ${ }^{12}$

Model Pembelajaran yang dilakukan penulis menggunakan metode PAAIKES, (Pembelajaran Aktif, Antusias, Inovatif, Kreatif, Efektif, dan Seru). Metode PAAIKES sebelum mulai menceritakan tentang Alkitab. Guru Sekolah Minggu melakukan percakapan tanya jawab dengan anak-anak, dengan tujuan agar meningkatkan pengetahuan yang aktif dan membangun pengetahuan tentang pembelajaran Alkitab. Guru Sekolah Minggu memperlihatkan gambar dengan melakukan pengajaran melalui menggambar dari tokoh Alkitab. Pola yang dilakukan adalah Pendampingan, yaitu Supervisi yang dilakukan oleh Guru Sekolah Minggu. Pendampingan dalam hal ini juga bertujuan agar Guru Sekolah Minggu dalam mengajar dapat memahami anak dan

${ }^{9}$ Cony Semiawan, Pendekatan Keterampilan Proses (Jakarta: Gramedia, 2010), 35.

${ }^{10}$ Dwiati Yulianingsih, "Upaya Guru Sekolah Minggu Dalam Meningkatkan Motivasi Belajar Alkitab Di Kelas Sekolah Minggu," Fidei: Jurnal Teologi Sistematika dan Praktika 3, no. 2 (2020): 285-301.

11 Paulus Lie, Mereformasi Sekolah Minggu (Yogyakarta: ANDI, 2003), 27.

12 Vivin Parinding, "Pengembangan Kreativitas Guru Sekolah Minggu Untuk Meningkatkan Perhatian Anak-Anak Sekolah Minggu Dalam Mengikuti Ibadah Dengan Menggunakan Metode Paikem," IAKN Toraja (IAKN Toraja, 2019)." 
PENERAPAN METODE PEMBELAJARAN PAAIKES ... (Yohanes Charly Panjaitan, Ferdinand Edu, Ivonne Sandra Sumual)

kemudian melakukan penyampaian pendapat terhadap apa yang telah dirancang dan dilaksanakan dalam pembelajaran Guru Sekolah Minggu

Model yang digunakan ialah pembelajaran melalui pemanfaatan media online. Guru Sekolah melakukan tugas mengajar melalui kreativitas mengajar yang terampil dalampower point dan youtube yang menjelaskan menjelaskan kisah tokoh Alkitab, setelah itu melakukan pendampingan guru Sekolah Minggu sesuai dengan pembahasan mingguan. Guru Sekolah Minggu melakukan perpaduan dengan permainan atau menggambar untuk meningkatkan fokus anak Sekolah Minggu. Penulis menggunakan metode yang sama seperti yang diterapkan oleh Guru Sekolah Minggu GBI Papua Restoration For Christ namun di sini penulis menambahkan gaya pembelajaran baru untuk meningkatkan keinginan anak dalam belajar Alkitab.

\section{Menyusun Rancangan Kegiatan dengan Kelompok}

Rancangan kegiatan ini disusun oleh kelompok dan guru Sekolah Minggu yang ada di GBI Papua Restoration For Christ untuk memperoleh keputusan yang tepat dan pelayanan yang terstruktur dalam melaksanakan Pengabdian Masyarakat Gereja selama 4 bulan penuh. Rancangan kegiatan ini berfokus kepada pengembangan kreativitas guru Sekolah Minggu dalam mengajar, yaitu menggunakan metode PAAIKES, (Pembelajaran Aktif, Antusias, Inovatif, Kreatif, Efektif, dan Seru) yang disusun seperti berikut:

\section{* Tema Kegiatan}

Adapun tema kegiatan Sekolah Minggu yang akan dilakukan, yaitu:

- Maret: Penciptaan

- April: Kejatuhan Manusia ke dalam Dosa

- Mei : Penebusan dan Paskah

- Juni : Kesetiaan

* Jenis Kegiatan

Jenis kegiatan yang akan dilakukan, seperti:

Maret

- Minggu, 21 Maret 2021 : Ibadah dan perkenalan

- Minggu, 28 Maret 2021 : Ibadah kreatif dan games

April

- Minggu, 11 April $2021 \quad$ : Ibadah

- Minggu, 25 April 2021 : Ibadah kreatif dan games

Mei

- $\quad$ Minggu, 9 Mei $202 \quad$ : Ibadah

- Minggu, 23 Mei 2021 : Ibadah kreatif dan games

Juni

- $\quad$ Minggu, 6 Juni $2021 \quad$ : Ibadah

- Minggu, 20 Juni 2021 : Ibadah kreatif dan games

* Peralatan yang Dibutuhkan

1. Laptop atau Hp

2. Kuota internet

3. Zoom Meeting

4. Alat tulis dan kertas

5. Dana untuk memberi hadiah kepada anak Sekolah Mingg 


\section{Pelaksanaan Pelayanan dengan Metode Pendekatan (Anak Sekolah Minggu)}

Pendekatan yang dilakukan adalah penerapan metode PAAIKES, (Pembelajaran Aktif, Antusias, Inovatif, Kreatif, Efektif, dan Seru) kepada anak Sekolah Minggu GBI Papua Restoration For Christ. Sesuai dengan rancangan kegiatan yang disusun, kegiatan ini diawali dengan perkenalan kepada anak Sekolah Minggu di GBI Papua Restoration For Christ, dilanjutkan dengan kegiatan ibadah kreatif dan penyampaian firman Tuhan seperti bukti dokumentasi pada gambar berikut:
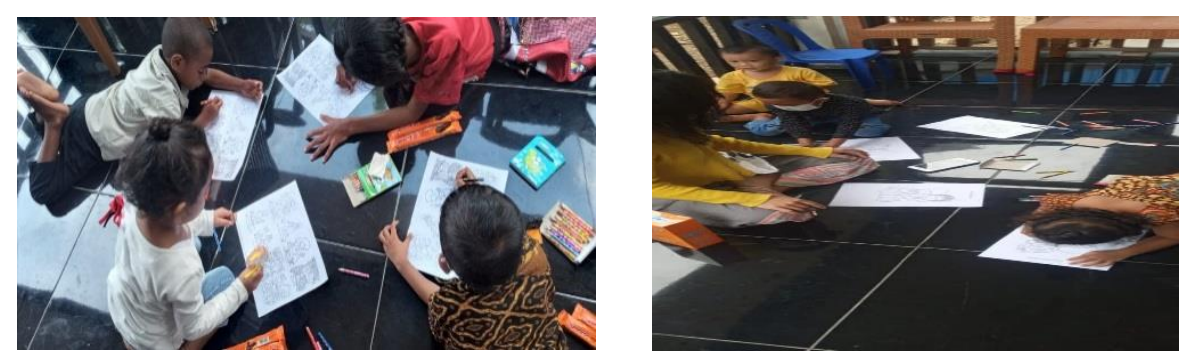

Gambar 1. Penyampaian materi
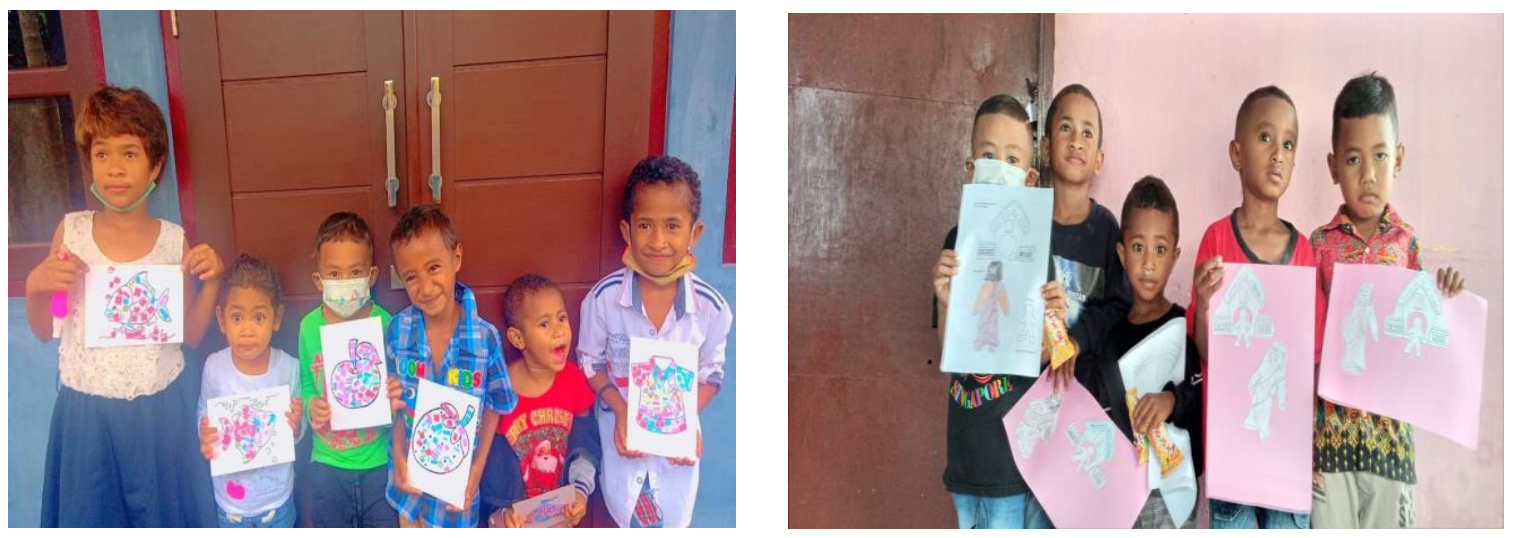

Gambar 2. Penyampaian materi Penebusan pada minggu pertama dan kedua

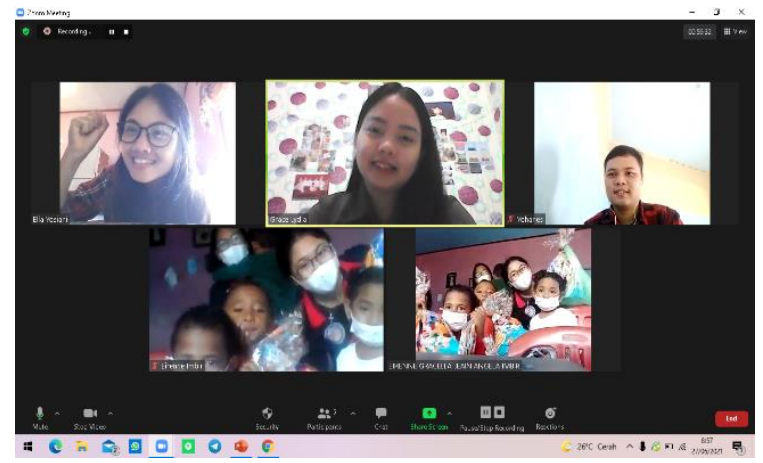

Gambar 3. Penyampaian materi Kesetiaan dan perpisahan dengan anak Sekolah Minggu pada minggu kedua

\section{Pelaksanaan Pelayanan dengan Metode Pendampingan}


PENERAPAN METODE PEMBELAJARAN PAAIKES ... (Yohanes Charly Panjaitan, Ferdinand Edu, Ivonne Sandra Sumual)

Metode pendampingan diawali dengan perkenalan kepada guru Sekolah Minggu di GBI Papua Restoration For Christ, agar dapat menciptakan suasana dan kerjasama yang baik sesuai dengan metode PAAIKES, (Pembelajaran Aktif, Antusias, Inovatif, Kreatif, Efektif, dan Seru). Dalam kesempatan ini juga dilakukan brainstorming terkait metode pelaksanaan kegiatan Pengabdian Masyarakat Gereja. Dalam pelaksanaan pendampingan, anggota kelompok yang berada di GBI Papua Restoration For Christ mengarahkan kedua guru sekolah minggu yang aktif dalam pelayanan anak Sekolah Minggu untuk menciptakan kreativitas saat ibadah Sekolah Minggu berlangsung. Metode Pendampingan dilakukan dengan dua cara, yakni online untuk brainstorming dan onside untuk praktik.

Berdasarkan Pengabdian kepada Masyarakat Gereja di GBI Papua Restoration for Christ, pengajaran Firman Tuhan kepada anak sekolah minggu yang tidak kreatif menyebabkan respon negatif dari anak-anak. Namun sebaliknya, jika metode PAAIKES diterapkan secara baik, maka anak sekolah minggu senang dan tidak bosan dalam mendengarkan dan memperhatikan cerita Alkitab. Mereka antusias dan semangat. Tim PkM Prodi S1 Teologi STT Bethel Indonesia mendapatkan respons positif dari para guru sekolah minggu dan pihak gereja karena telah memberikan warna baru dalam mengajar anak sekolah minggu yang menyebabkan terjadi peningkatan jumlah kehadiran anak .

\section{UCAPAN TERIMA KASIH}

Tim mengucapkan terima kasih yang sebesar-besarnya kepada Kepala Prodi Teologi S1 STT Bethel Indonesia yang telah mendukung secara moral dan materil sehingga pelaksanaan kegiatan PkM ini dapat berjalan dengan baik dan berdampak bagi anak sekolah minggu GBI Papua Restoration For Christ. Tim juga mengucapkan terima kasih untuk saudara Anggi Maringan Hasiholan yang telah mengarahkan penulisan artikel ini sehingga dapat dijadikan muatan ilmiah dalam penulisan artikel Pengabdian kepada Masyarakat.

\section{KESIMPULAN}

Berdasarkan hasil Pengabdian Masyarakat Gereja yang dilakukan di GBI Papua Restoration For Christ, metode mengajar memberi pengaruh yang besar bagi kemauan anak Sekolah Minggu untuk aktif dan antusias saat mengikuti ibadah dan mendengarkan firman Tuhan. Berdasarkan kegiatan ini juga diperoleh pemahaman bahwa metode mengajar yang tepat pada setiap gereja dapat dibentuk dengan pendampingan yang dilakukan oleh mentor atau tim lainnya yang lebih kompeten dalam bidang mengajar anak Sekolah Minggu. Jika metode PAAIKES ini dipupuk melalui pendampingan seperti yang telah dilakukan saat Pengabdian Masyarakat Gereja, maka kurangnya antusias anak Sekolah Minggu dalam beribadah dan penurunan anak Sekolah Minggu secara kuantitas dapat diatasi dengan baik. 


\section{DAFTAR PUSTAKA}

Hoch, Jodi, Janet Lee, and Susan. Berbagai Aktivitas Asyik Untuk Anak Di Sekolah Minggu Kelompok Bermain Dan Rumah. Jakarta: BPK Gunung Mulia, 2004.

Kristiono, Tanto, and Deo Putra Perdana. "Hambatan Dan Pelayanan Guru Sekolah Minggu Di Gereja Kristen Jawa Jebres Surakarta” 1, no. 2 (2019): 91.

Kurniawati, Meike, and Ninawati. "Seminar Mengajar Kreatif." Prosiding Seminar Hasil Pengabdian Kepada Masyarakat (2018): 468-472.

Lie, Paulus. Mereformasi Sekolah Minggu. Yogyakarta: ANDI, 2003.

Munandar, Utami. Mengembangkan Bakat Dan Kreativitas Anak Sekolah. Jakarta: Gramedia Widiasarana Indonesia, 2012.

_- - Pengembangan Kreativitas Anak Berbakat. Jakarta: Rineka Cipta, 2009.

Parinding, Vivin. "Pengembangan Kreativitas Guru Sekolah Minggu Untuk Meningkatkan Perhatian Anak-Anak Sekolah Minggu Dalam Mengikuti Ibadah Dengan Menggunakan Metode Paikem." IAKN Toraja. IAKN Toraja, 2019.

Semiawan, Cony. Pendekatan Keterampilan Proses. Jakarta: Gramedia, 2010.

Slameto. Belajar Dan Faktor-Faktor Yang Mempengaruhi. Jakarta: Rineka Cipta, 2010.

Yulianingsih, Dwiati. "Upaya Guru Sekolah Minggu Dalam Meningkatkan Motivasi Belajar Alkitab Di Kelas Sekolah Minggu." Fidei: Jurnal Teologi Sistematika dan Praktika 3, no. 2 (2020): 285-301. 